\title{
HYPERTEXTING THROUGH THE REGULATIONS
}

Imagine being able to get impartial advice from a computer to help one through the Confusion of Regulatory Agricultural Practices surrounding field tests of genetically modified organisms: a hypertext helpmate to tell you which agency to ap- proach; a digital doyen of biosafety principles and practice; a 16-bit subordinate conversant in species-specific safeguards. Stop dreaming; the system already exists and has been used to obtain a permit to field test genetically engineered rice in the U.S. It is an expert system known as the Program for Preparing Applications to Conduct Biotechnology Field Tests (PPACBFT*).

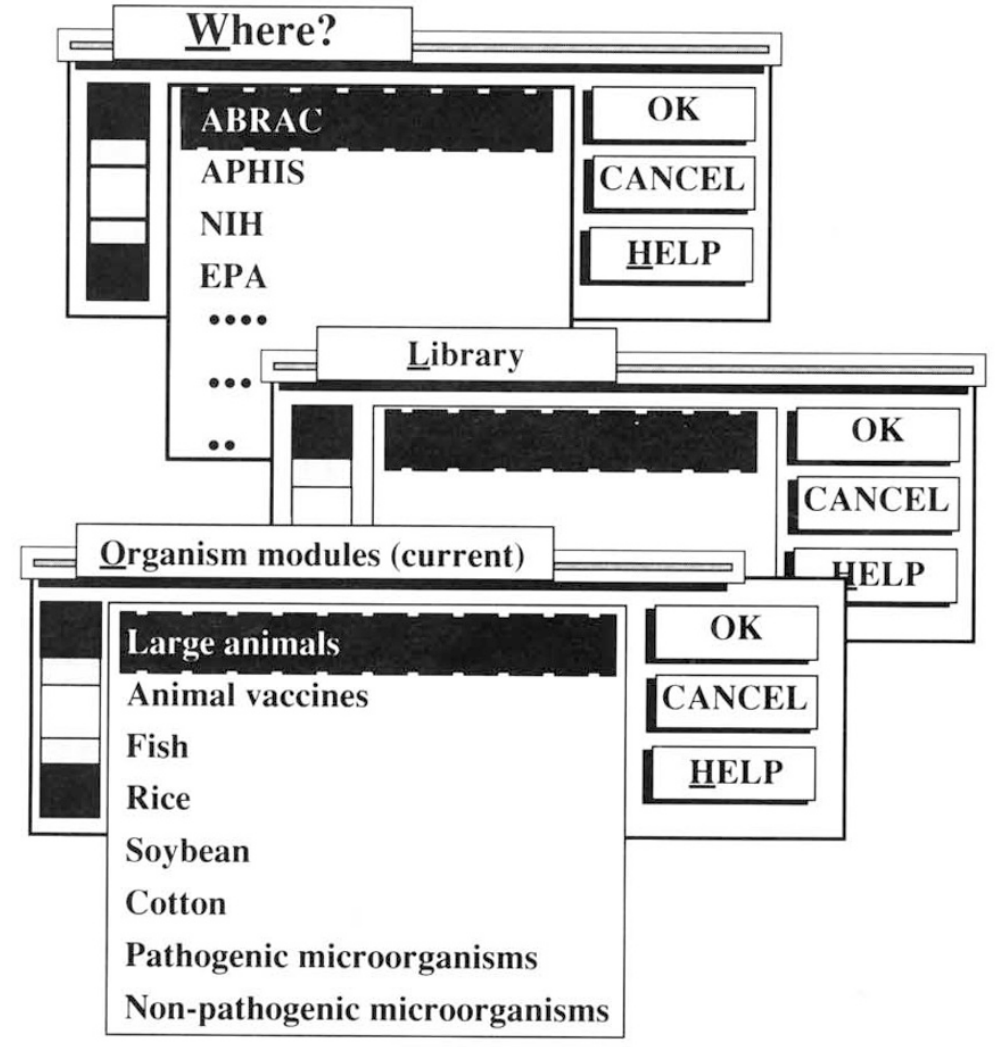

\section{WHICH AGENCY?}

The system first helps users identify which of the various regulatory bodies has jurisdiction over the intended field test experiment. At present the system covers only U.S. agencies but modules for additional international, national or local authorities could be included.

\section{WHAT SHOULD YOU KNOW?}

The second stage of the program is, in essence, a library of information on health and environmental principles relevant to planning field tests compiled from the scientific and regulatory literature. Users access the information, which is organized as hypertext, either through keywords or through a "first level" of text that is a general statement on the problem and principles of field-testing genetically engineered organisms.

\section{Filling IN FORMS.}

The third module of the expert system is designed to help users meet the specific requirements for filing field test applications. There are separate modules for each of eight organism groups; large animals, animal vaccines, fish, rice, soybean, cotton, pathogenic microorganisms and non-pathogenic microorganisms. After selecting one, the user begins to "fill in the form" in response to interrogation by the system. The responses allow the user to "skip over" irrelevant parts of the "form." Although it covers issues from the molecular biology of the organism to the geography of the site (see figure), the system is friendly, proffering recommendations or a range of possible responses based on previous expert panel recommendations and successful test applications. Users will be alerted to subject areas where non-compliance could lead to denial of permission to test. The final system output is a draft application to the review body which may need little more than a final editing. -John Hodgson

Chemical confinement

Security

Biological monitoring

Personnel training

Termination of experiment

Environmental considerations

Public information

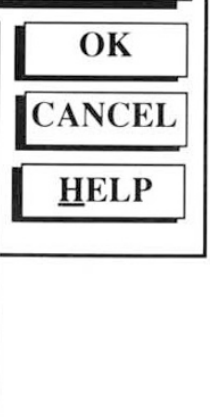

* PPACBFT was developed by W.Schuh, R. Bankert, and J.Travis (Department of Plant Pathology, The Pennsylvania State University, University Park, $P A), P$. Love (NBIAP/USDA, Washington, DC), and D. King (Department of Biochemistry and Nutrition, Virginia Tech University, Blacksburg, VA) with support from USDA/NBIAP. It can be obtained free of charge from NBIAP/ USDA, Aerospace Building, Suite 330, 901 D Street SW, Washington, DC 20250-2200, U.S. For support and information, telephone (I) 703-321-3747 (13:00-16:00 EST). 